\title{
CONTEÚDO DE MIRICETINA, QUERCETINA E KAEMPFEROL EM CHÁS COMERCIALIZADOS NO BRASIL ${ }^{1}$
}

\author{
Simara MATSUBARA², Delia B. RODRIGUEZ-AMAYA ${ }^{2, *}$
}

\begin{abstract}
RESUMO
Os teores de miricetina, quercetina e kaempferol foram determinados em uma marca de ban-chá, duas de chá verde e quatro de chá preto. Analisaram-se três lotes para cada marca em duplicata por cromatografia líquida de alta eficiência. Quercetina (2,5-3,4 mg/g folha seca) predominou em todas as amostras, seguida por kaempferol (1,0-2,0 mg/g folha seca), com exceção de uma amostra na qual kaempferol e miricetina tiveram teores iguais. Houve variação entre os tipos de chás e mesmo entre marcas do mesmo tipo. Miricetina (traços - 1,9 mg/g folha seca) foi o flavonol, que mais variou e que esteve em menor nível nos chás pretos. Outros chás muito consumidos no Brasil também foram investigados. A miricetina não foi encontrada em chás de frutas (maçã e morango) e de ervas (erva doce, camomila, erva cidreira, hortelã, boldo, mate e erva mate), enquanto que quercetina foi encontrada em quatro chás (camomila, boldo, morango e erva mate) e kaempferol, em dois chás (boldo e erva-mate), em concentrações de 0,4 a 2,5 e 0,4 a $2,6 \mathrm{mg} / \mathrm{g}$ de folha seca, respectivamente. Concluiu-se que estes chás são fontes de flavonóis na dieta brasileira, embora com teores menores que em chás verde e preto.

Palavras-chave: flavonóis, chá, CLAE.
\end{abstract}

\section{SUMMARY}

MYCIRETIN, QUERCETIN AND KAEMPTEROL CONTENTS IN TEAS COMMERCIALIZED IN BRAZIL. The myricetin, quercetin and kaempferol contents of a brand of "ban-chá", two brands of green tea and four brands of black tea were determined. Three lots of each brand were analysed in duplicate by high performance liquid chromatography. Quercetin (2.5-3.4 mg/g of dry leaf) predominated in all samples, followed by kaempferol (1.0-2.0 mg/g of dry leaf), with the exception of one sample, in which kaempferol and myricetin had the same levels. There was variation between different types of tea and even between brands of the same type of tea. Myricetin (trace-1.9 mg/g of dry leaf) was the flavonol, that varied the most and was present at lower levels in black tea. Other teas widely consumed in Brazil were also investigated. Myricetin was not found in teas of fruits (apple and strawberry) and herbs (anise, camomile, lemon grass, peppermint, boldo, maté, green maté), but quercetin was found in four teas (camomile, boldo, strawberry, green maté) and kaempferol, in two teas (boldo, green maté) at concentrations of 0.4 to $2.5 \mathrm{mg} / \mathrm{g}$ and 0.4 to $2.6 \mathrm{mg} / \mathrm{g}$ of dry leaf, respectively. It is concluded that these teas are sources of flavonols in the Brazilian diet, although at levels lower than those of green and black tea.

Keywords: flavonols, tea, HPLC analysis.

\section{1 - INTRODUÇÃO}

Flavonóides são polifenóis que ocorrem naturalmente em alimentos de origem vegetal e são comuns em dietas de todo o mundo. São metabólitos secundários de plantas e podem ser subdivididos em seis classes: flavonas, flavanonas, isoflavonas, flavonóis, flavanóis e antocianinas [1, 8]. O que diferencia os flavonóis dos demais flavonóides é a presença do grupo hidroxílico (na posição 3) e do grupo carbonílico (na posição 4) no anel C (Figura 1). Os flavonóis ocorrem em alimentos geralmente como $O$-glicosídeos, com mono, di ou trissacarídeos ligados em sua maioria, na posição 3, e em alguns casos, na posição 7. Os glicosídeos mais encontrados são glicose, galactose, ramnose e frutose.

O chá, uma das bebidas mais consumidas no mundo, é uma das fontes mais ricas em flavonóides. Produzidos a partir de folhas de Camellia sinensis, os chás verde e preto são largamente consumidos em países orientais e ocidentais,

\footnotetext{
${ }^{1}$ Recebido para publicação em 7/6/2005. Aceito para publicação em 28/4/2006 (001538)

${ }^{2}$ Departamento de Ciência de Alimentos, Faculdade de Engenharia de Alimentos, Universidade Estadual de Campinas

Caixa Postal 6121

CEP 13083-862 - Campinas (SP)

*A quem a correspondência deve ser enviada
}

respectivamente. O chá verde é constituído de folhas secas colhidas de diferentes partes da planta, o que determina os vários tipos de chás disponíveis. Já o chá preto passa por diversas etapas de processamento, dentre elas a de "fermentação", que consiste, na verdade, de uma oxidação enzimática dos flavanóis a teaflavinas, que constituem um grupo característico deste tipo de chá.

No Brasil, o chá mate é a infusão mais consumida [11], especialmente na Região Sul do País, mas outros chás também são comercializados, como os de frutas (maçã e morango) e de ervas (erva doce, erva cidreira, camomila, hortelã, boldo). Muitos dos chás de ervas são consumidos para fins medicinais segundo a sabedoria popular. Em alguns Estados brasileiros, a erva-mate é bastante consumida como chimarrão ou tererê, diferindo pela forma de preparo, como a temperatura da água de infusão.

Acredita-se que os flavonóides presentes em chás fazem deles alimentos funcionais. No entanto, os estudos sobre o potencial efeito benéfico dos flavonóides para a saúde humana são ainda inconsistentes ou insuficientes, apesar da intensa investigação sobre este assunto discutida em numerosos artigos de revisão $[2-5,7,9,10,13,15,16$, 18, 20, 21]. Embora muitos dos trabalhos envolvessem os chás verde e preto e não substâncias específicas, os 


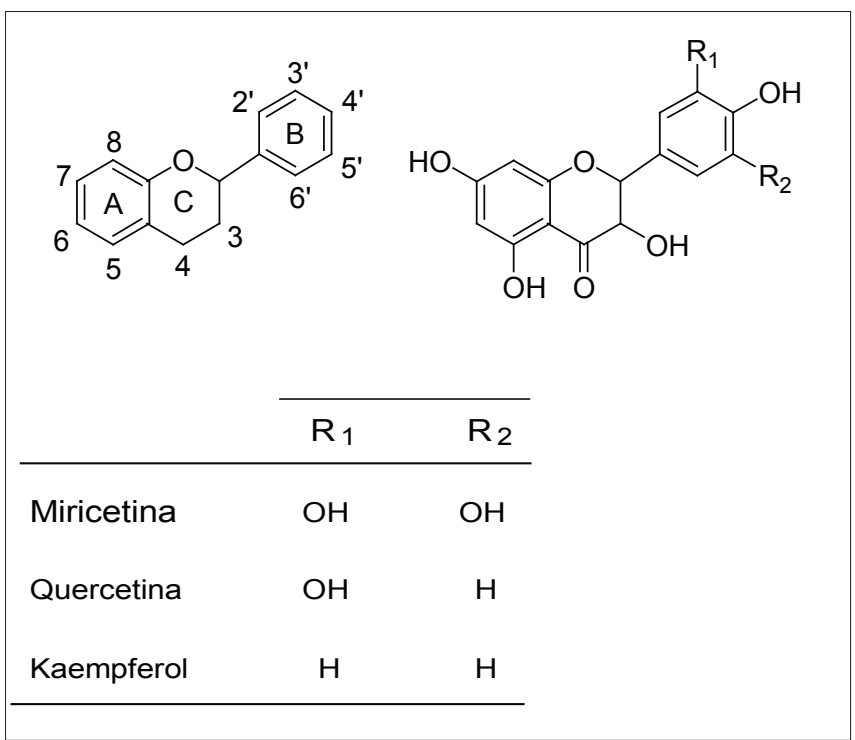

FIGURA 1 - Estrutura básica de flavonóides e de flavonóis agliconas presentes em chás

efeitos benéficos são geralmente atribuídos às catequinas e teaflavinas. Além das catequinas e teaflavinas, os chás também contêm flavonóis como miricetina, quercetina e kaempferol.

Para a continuação dos estudos, é imprescindível a disponibilidade de dados confiáveis sobre os teores destes flavonóides em chás. No presente trabalho, os flavonóis miricetina, quercetina e kaempferol foram quantificados, na forma de agliconas, em chás comercializados no Brasil, dentre eles, chás verde, preto, mate, de frutas e de outras ervas. A determinação na forma de agliconas simplifica a análise.

\section{2 - MATERIAL E MÉTODOS}

\section{1 - Amostras}

Foram compradas no mercado local (Campinas, SP) diversas marcas de chás, sendo: verde (Camellia sinensis), três marcas; preto (Camellia sinensis), quatro marcas; erva doce (Pimpinella anisum L.), uma marca; camomila (Matricaria chamomilla L.), três marcas; erva cidreira (Cymbopogon citratus (DC.) Stapf.), uma marca; hortelã (Mentha piperita L.), uma marca; boldo (Peumus boldus), três marcas; morango (Fragaria vesca L.), uma marca; maçã (Malus domestica), uma marca; mate (Ilex paraguariensis), uma marca; e erva mate (Ilex paraguariensis), três marcas. O produto "Ban-chá" é um chá verde constituído de folhas mais velhas e rasteiras das plantas de Camellia sinensis. O chá verde propriamente dito é feito de folhas mais novas e tenras. A diferença da matéria-prima reflete no sabor, cor e, possivelmente, nos teores de flavonóides. De todos os produtos analisados, apenas uma marca de chá verde e uma de camomila têm matéria-prima importada (Alemanha e Argentina, respectivamente), ambas as marcas sendo embaladas no Brasil. As embalagens varia- ram de 9 a 1.000 g; a diferença deve-se ao fato de que as ervas mate, o ban-chá e uma das marcas de chá verde que foram comercializadas a granel. As demais marcas foram adquiridas em sachês. Para cada marca, três lotes foram analisados em duplicatas.

\section{2 - Padrões e reagentes}

Os padrões de quercetina, miricetina e kaempferol utilizados neste estudo foram adquiridos da Sigma Chemical Co. (St. Louis, EUA). Soluções-estoque foram preparadas com metanol, em concentrações em torno de $1 \mathrm{mg} / \mathrm{mL}$, armazenadas a $-20^{\circ} \mathrm{C}$ por no máximo dois meses. Para a preparação de soluções-trabalho, pequenos volumes de solução-estoque tiveram o metanol evaporado por fluxo de nitrogênio e os flavonóis redissolvidos em solução aquosa de metanol 50\% v/v. Em testes preliminares, os padrões injetados em metanol puro apresentaram caudas. Por outro lado, os padrões dissolvidos em água pura apresentaram baixa estabilidade. Por isso, os padrões foram estocados em metanol e a substituição por metanol aquoso foi realizada imediatamente antes da injeção.

Metanol, $\mathrm{HCl}$ e ácido fórmico, todos de grau analítico, foram adquiridos da Merck (Darmstadt, Alemanha), e o butil-hidroxianisol, da Sigma Chemical Co. (St. Louis, EUA). O metanol grau CLAE (cromatografia líquida de alta eficiência) foi adquirido da Mallinckrodt (Kentucky, EUA).

\section{3 - Preparação de amostras e hidrólise}

As folhas do mesmo lote foram misturadas e pesadas. Para manter a presença da embalagem durante a extração mesmo depois de pesadas, as folhas foram reembaladas em sachês cedidos pela Der Teeladen (São Paulo, SP) e fechadas por termossoldagem de uma fita de polietileno de baixa densidade. Os novos sachês, assim como as folhas preparadas a granel, com peso de $5 \mathrm{~g}$, foram colocados em $500 \mathrm{~mL}$ de água destilada fervente e deixados por $5 \mathrm{~min}$ [6], com ligeiras agitações no início, meio e final do período. Em seguida, a infusão foi filtrada a vácuo em papel de filtro no caso de folhas a granel, ou o sachê removido da infusão, sendo então resfriadas à temperatura ambiente. O volume foi elevado a $500 \mathrm{~mL}$ com água destilada. A fim de melhor padronizar a extração, ao final do tempo de infusão, as embalagens foram retiradas e imersas em aproximadamente $85 \mathrm{~mL}$ de água e agitadas, sendo esta água posteriormente utilizada para completar o volume de $500 \mathrm{~mL}$ para o qual foram elevados os extratos. O mesmo foi realizado com as amostras filtradas.

Para a hidrólise dos flavonóis [6], $15 \mathrm{~mL}$ destes extratos foram adicionados de $40 \mathrm{~mL}$ de metanol aquoso $62,5 \%$ (com $2 \mathrm{~g} / \mathrm{L}$ butil-hidroxianisol) e, a esta mistura, $10 \mathrm{~mL} \mathrm{HCl} \mathrm{6M.}$ A hidrólise procedeu em banho com refluxo a $90^{\circ} \mathrm{C}$ por 2 h. Após este período, o extrato foi resfriado em banho de gelo e elevou-se o volume com metanol em balão de 100 $\mathrm{mL}$. Aproximadamente $2 \mathrm{~mL}$ do hidrolisado foi filtrado em filtro de politetrafluoretileno 0,22 $\mu \mathrm{m}$ hidrofóbico (Millipore, EUA) para posterior injeção. 


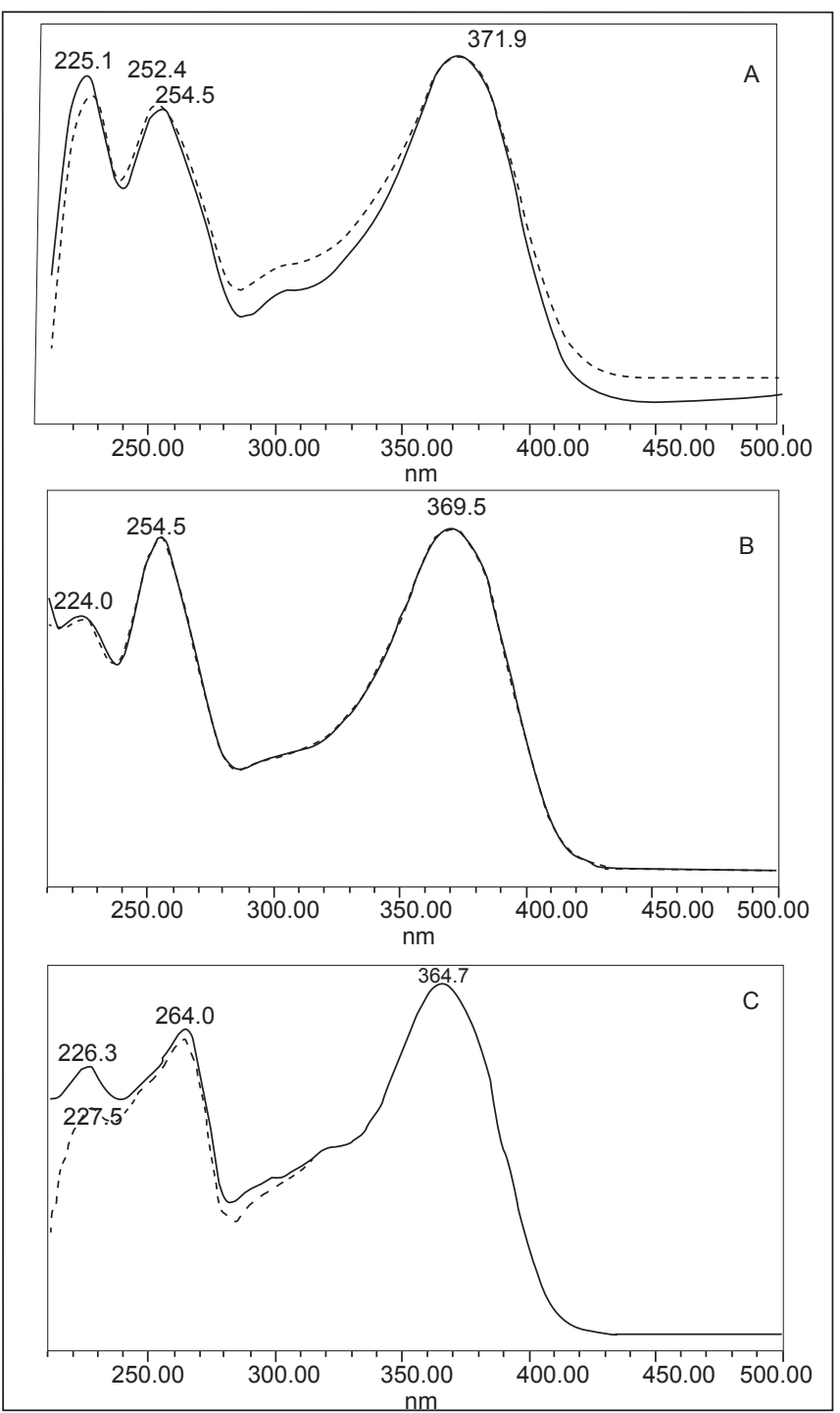

FIGURA 2 - Sobreposição de espectros de absorção de padrões (- . - -) e de amostras (- $\longrightarrow$ de miricetina (A), quercetina (B) e kaempferol (C) obtidos pelo detector de arranjo de diodos

\section{4 - Cromatografia}

A determinação dos flavonóis foi realizada por CLAE. As separações cromatográficas foram realizadas em coluna de fase reversa Novapak $\mathrm{C}_{18}(3,9 \mathrm{~mm} \mathrm{x}$ $150 \mathrm{~mm}, 4 \mu \mathrm{m}$ ) (Waters, Milford, MA). O equipamento foi um cromatógrafo líquido Waters, constituído de bomba quaternária modelo 600, detector de arranjo de diodos modelo 996, injetor manual Rheodyne, controlado pelo software Millennium 32.

A eluição em gradiente teve como fase móvel solvente A, água/ácido fórmico (99,7:0,3, v/v) e solvente B, metanol/ ácido fórmico $(99,7: 0,3, \mathrm{v} / \mathrm{v})$. A programação foi a seguinte: de 70 a $50 \%$ A em 10 min e de 50 a $30 \%$ A em 20 min, sempre em gradiente linear. A vazão foi de $1,0 \mathrm{~mL} / \mathrm{min}$. $\mathrm{O}$ volume de amostra injetado foi de $20 \mu \mathrm{L}$. A identificação dos componentes baseou-se nos espectros obtidos entre 210 e $600 \mathrm{~nm}$ pelo detector de arranjo de diodos (Figu- ra 2), nos tempos de retenção, comparados com os dos padrões injetados diariamente, e co-cromatografia com os padrões.

Os flavonóis foram quantificados a $370 \mathrm{~nm}$ por padronização externa. Os valores obtidos $\mathrm{em} \mathrm{mg} / \mathrm{L}$ de infusão foram transformados também em $\mathrm{mg} / \mathrm{g}$ de folha seca, considerando os $5 \mathrm{~g}$ de folha utilizados para a preparação da infusão.

\section{5 - Curva padrão}

Curvas padrão com cinco pontos foram construídas para quantificação dos flavonóis em concentrações baseadas nas estimativas dos seus teores nos chás. De uma solução-mãe em metanol, contendo uma mistura dos padrões em proporção relativa semelhante a das amostras, volumes de 1, 2, 3, 4 e $5 \mathrm{~mL}$ foram retirados para balões de $5 \mathrm{~mL}$. O solvente foi evaporado, os flavonóis redissolvidos em metanol aquoso $50 \%$ e o volume elevado a $5 \mathrm{~mL}$. Cada solução constituiu um ponto, o qual foi injetado em triplicata.

\section{3 - RESULTADOS E DISCUSSÃO}

\section{1 - Características da curva padrão}

As curvas padrão passaram pela origem e apresentaram-se lineares nas faixas de concentração que abrangeram as amostras. A Tabela 1 mostra os dados obtidos de cada curva.

Os coeficientes de correlação foram bons para quercetina e kaempferol, ambos maiores que 0,99. Para miricetina, este coeficiente foi mais baixo. Isto ocorreu porque sua concentração foi bem menor que as dos outros flavonóis. Os coeficientes de variação entre as triplicatas de cada ponto foram, em média, de 1,7 a 2,5, com a miricetina apresentando a maior variação também pela sua concentração bem menor.

TABELA 1 - Propriedades das curvas padrão de flavonóis

\begin{tabular}{lccc}
\hline Flavonol & $\begin{array}{c}\text { Faixa de } \\
\text { concentração } \\
(\boldsymbol{\mu g} / \mathbf{m L})\end{array}$ & $\begin{array}{c}\text { Coeficiente de } \\
\text { correlação }\end{array}$ & $\begin{array}{c}\text { Coeficiente de } \\
\text { variação entre } \\
\text { triplicatas (\%) }\end{array}$ \\
\hline Miricetina & $1,8-9,1$ & 0,9885 & 2,5 \\
Quercetina & $11,4-56,8$ & 0,9944 & 1,7 \\
Kaempferol & $8,9-44,4$ & 0,9972 & 1,8 \\
\hline
\end{tabular}

${ }^{a}$ Médias de 15 valores

\section{2 - Repetitividade}

Para avaliar a precisão intralaboratorial do método como um todo, foram realizados testes de repetitividade com as amostras de chás verde e preto. Duplicatas de uma mesma embalagem foram analisadas para cada marca de produto. Os coeficientes de variação (CV) entre duplicatas de chás verdes foram os seguintes: miricetina, $3,0 \%$; quercetina, 4,1\%; kaempferol, 1,9\% (médias de seis amostras).

Em chás pretos, os CVs foram: miricetina, 3,3\% (média de quatro amostras); quercetina, 4,4\%; kaempferol, de 


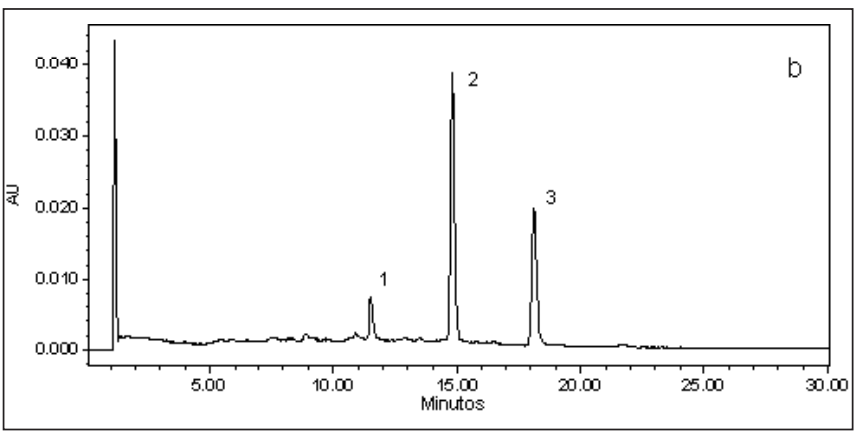

FIGURA 3 - Cromatogramas de amostras de chás: (a) verde e (b) preto. Condições cromatográficas: 70 a 50\%A em 10 min e de 50 a 30\%A em 20 min, sendo A: H2O/ácido fórmico (99,7:0,3, v/v) e B: MeOH/ácido fórmico (99,7:0,3, v/v), razão 1,0 mL/min. Picos: miricetina (1), quercetina (2) e kaempferol (3).

2,5\% (médias de oito amostras para quercetina e kaempferol). Duas marcas de chá preto continham miricetina em quantidades menores que $0,5 \mathrm{mg} / \mathrm{g}$ de folha seca, o que resultou em CV de 20\%. Deste resultado, observou-se que para a miricetina nestas amostras, o limite de quantificação foi em torno de $0,5 \mathrm{mg} / \mathrm{g}$ de folhas, equivalente à injeção de $15 \mathrm{mg}$ de miricetina.

\section{3 - Teores de flavonóis em chás verde e preto}

A Figura 3 mostra cromatogramas típicos de flavonóis em chás verde e preto. A Tabela 2 apresenta os teores de flavonóis em chás verde e preto comercializados em Campinas (SP). Em todas as amostras, a quercetina predominou, seguida por kaempferol, com exceção de uma amostra, na qual o teor de kaempferol e quercetina foram iguais. Observou-se variação dos flavonóis entre os tipos de chás e mesmo entre marcas do mesmo tipo. A miricetina foi o componente com teores mais variados. Enquanto em chás pretos sua concentração variou entre traços e $0,7 \mathrm{mg} / \mathrm{g}$ de folha seca, em chás verdes variou entre 0,7 e 1,9 mg/g de folha seca.

A quantidade menor em chás pretos pode ser decorrente do processamento. As amostras de ban-chá e chá verde marca A eram do mesmo fabricante. Os teores menores encontrados no ban-chá reforçam a idéia de que as folhas mais tenras, que constituem o chá verde, apresentam melhor qualidade não apenas sensorial, mas também quanto à presença de flavonóides. Outra característica era a falta de homogeneidade na amostra de ban-chá, que além de folhas mais velhas, tinha grande presença de galhos, diferenciando-se do chá verde, onde havia apenas folhas.

TABELA 2 - Teores de flavonóis em chás verde e preto*

\begin{tabular}{|c|c|c|c|c|c|c|c|}
\hline \multirow{2}{*}{ Amostra } & \multirow{2}{*}{ Marca** } & \multicolumn{2}{|c|}{ Miricetina } & \multicolumn{2}{|c|}{ Quercetina } & \multicolumn{2}{|c|}{ Kaempferol } \\
\hline & & $\mathrm{mg} / \mathrm{g}$ folha seca & mg/L infusão & $\mathrm{mg} / \mathrm{g}$ folha seca & mg/L infusão & $\mathrm{mg} / \mathrm{g}$ folha seca & mg/L infusão \\
\hline Ban-chá & $A$ & $1,1 \pm 0,1$ & $1,6 \pm 0,1$ & $2,5 \pm 0,1$ & $3,8 \pm 0,2$ & $1,0 \pm 0,1$ & $1,5 \pm 0,1$ \\
\hline \multirow{2}{*}{ Chá verde } & $A$ & $1,9 \pm 0,1$ & $2,8 \pm 0,1$ & $3,4 \pm 0,1$ & $5,2 \pm 0,1$ & $1,9 \pm 0,1$ & $2,8 \pm 0,1$ \\
\hline & $B$ & $0,7 \pm 0,1$ & $1,0 \pm 0,1$ & $2,5 \pm 0,1$ & $3,7 \pm 0,1$ & $1,1 \pm 0,1$ & $1,6 \pm 0,1$ \\
\hline \multirow{4}{*}{ Chá preto } & $B$ & $0,7 \pm 0,1$ & $1,1 \pm 0,1$ & $3,2 \pm 0,2$ & $4,8 \pm 0,3$ & $2,0 \pm 0,1$ & $3,0 \pm 0,2$ \\
\hline & C & $\operatorname{traço} 0^{* \star *}$ & traço & $3,1 \pm 0,2$ & $4,7 \pm 0,3$ & $1,6 \pm 0,1$ & $2,4 \pm 0,1$ \\
\hline & $\mathrm{D}$ & traço & traço & $2,7 \pm 0,5$ & $4,0 \pm 0,7$ & $2,0 \pm 0,1$ & $3,0 \pm 0,2$ \\
\hline & $E$ & $0,5 \pm 0,2$ & $0,7 \pm 0,2$ & $3,2 \pm 0,1$ & $4,7 \pm 0,2$ & $1,8 \pm 0,2$ & $2,7 \pm 0,3$ \\
\hline
\end{tabular}

*Médias e desvios padrão de três lotes diferentes analisados em duplicatas

**Marcas com a mesma letra foram fabricadas pela mesma empresa

***Aproximadamente $0,3 \mathrm{mg} / \mathrm{g}$ de folha, o limite de quantificação do método foi de $0,5 \mathrm{mg} / \mathrm{g}$ folha seca

A matéria-prima do chá verde marca B foi importada da Alemanha, sendo as demais amostras de produção brasileira. Ban-chá e chá verde marca A estavam a granel, e as demais amostras, em sachês.

Tabela 3 - Teores de flavonóis em chás comercializados no Brasil

\begin{tabular}{|c|c|c|c|c|c|}
\hline \multirow{2}{*}{ Amostras } & & \multirow[b]{2}{*}{ Marca** $^{*}$} & \multicolumn{3}{|c|}{ Concentração (mg/g folha seca)* } \\
\hline & & & Miricetina & Quercetina & Kaempferol \\
\hline Erva doce & Foeniculum vulgare & $A$ & $n d^{* * *}$ & nd & nd \\
\hline \multirow[t]{3}{*}{ Camomila } & Matricaria chamomilla & $A$ & nd & $0,9 \pm 0,1$ & nd \\
\hline & & $B$ & nd & $0,7 \pm 0,1$ & nd \\
\hline & & $\mathrm{C}$ & nd & $0,6 \pm 0,1$ & nd \\
\hline Erva cidreira & Cymbopogon citratus & A & nd & nd & nd \\
\hline Hortelã & Mentha piperita & A & nd & nd & nd \\
\hline \multirow[t]{3}{*}{ Boldo } & Peumus boldus & B & nd & $1,6 \pm 0,3$ & $2,5 \pm 0,5$ \\
\hline & & C & nd & $2,0 \pm 0,1$ & $2,0 \pm 0,2$ \\
\hline & & $\mathrm{D}$ & nd & $2,0 \pm 0,1$ & $2,6 \pm 0,3$ \\
\hline Morango & Fragaria vesca & C & nd & $0,4 \pm 0,1$ & nd \\
\hline Maçã & Pyrus malus & A & nd & nd & nd \\
\hline Mate & Ilex paraguariensis & B & nd & nd & nd \\
\hline \multirow[t]{3}{*}{ Erva mate } & Ilex paraguariensis & $E$ & nd & $2,5 \pm 0,1$ & $0,4 \pm 0,1$ \\
\hline & & $\mathrm{F}$ & nd & $2,0 \pm 0,3$ & $0,3 \pm 0,1$ \\
\hline & & G & nd & $3,3 \pm 0,3$ & $0,6 \pm 0,1$ \\
\hline
\end{tabular}

*Média e desvio padrão de 3 lotes diferentes **Marcas com a mesma letra foram fabricados pela mesma firma

***Não detectado, limite de detecção $=0,1 \mathrm{mg} / \mathrm{g}$

A matéria-prima para a camomila marca A foi importada da Argentina. Com exceção da erva-mate, que estava a granel, as demais amostras estavam em sachês. 
TOYODA et al. [17] quantificaram os mesmos flavonóis em diversos tipos de chás, encontrando, para chá verde teores em $\mathrm{mg} / \mathrm{g}$ de folha seca de 1,3 para miricetina, 1,6 para quercetina e 1,5 para kaempferol. Com exceção de quercetina, para o qual os teores relatados são superiores ao presente estudo $(2,5$ a $3,4 \mathrm{mg} / \mathrm{g}$ folha seca), os valores para miricetina e kaempferol são concordantes. WANG

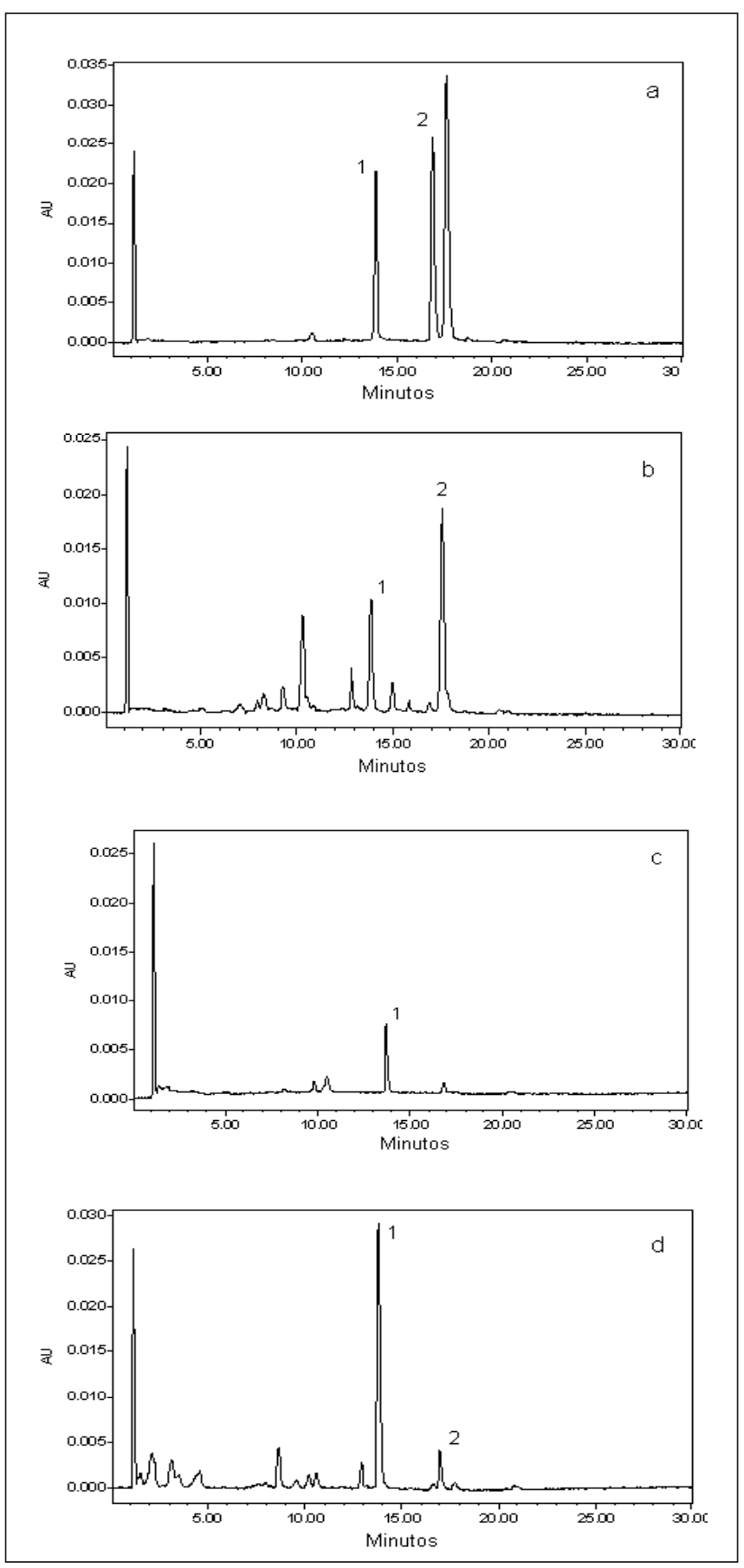

FIGURA 4 - Cromatogramas de amostras de chás: (a) camomila, (b) boldo, (c) morango e (d) erva mate. Condições cromatográficas: 70 a 50\%A em 10 min e de 50 a 30\%A em 20 min, sendo A: H2O/ácido fórmico (99,7:0,3, v/v) e B: MeOH/ácido fórmico $(99,7: 0,3, \mathrm{v} / \mathrm{v})$, vazão $1,0 \mathrm{~mL} / \mathrm{min}$. Picos: quercetina (1) e kaempferol (2) e HELLIWELL [19] encontraram, em mg/g de folha seca, 0,8 a 1,6 e 0,2 a 0,5 de miricetina, 1,8 a 4,0 e 1,0 a 3,0 de quercetina e 1,6 a 3,3 e 1,7 a 2,3 de kaempferol em quatro tipos de chá verde e dois tipos de chá preto, respectivamente, valores também semelhantes aos obtidos no presente trabalho. Já MATTILA et al. [14] relataram níveis bem mais baixos.

No trabalho de HERTOG et al. [6], em diferentes marcas de chás pretos, os teores, em mg/L de extrato, variaram entre 1,7 e 5,2 para miricetina, 10 e 25 para quercetina e 6 e 17 para kaempferol. Estes valores são superiores aos obtidos no presente trabalho. Em chás verdes, as faixas foram de 5,2 a 12, 14 a 23 e 9 a 15 $\mathrm{mg} / \mathrm{L}$ de extrato para miricetina, quercetina e kaempferol, respectivamente, teores também maiores que os encontrados nos chás verdes disponíveis no Brasil. Já os conteúdos de quercetina e de kaempferol em chá preto analisado por KARAKAYA e EL [12] são muito menores aos encontrados nas amostras brasileiras (35 e $110 \mu \mathrm{g} / \mathrm{L}$, respectivamente). Foram utilizados $5 \mathrm{~g}$ de folha seca para $250 \mathrm{~mL}$ de água fervente por $10 \mathrm{~min}$ no trabalho de KARAKAYA e EL [12], em comparação com $5 \mathrm{~g}$ por $500 \mathrm{~mL}$ de água fervente por 5 min do presente trabalho e de HERTOG et al. [6].

\section{4 - Estudo de flavonóis em outros chás}

Como já ressaltado, o consumo de chás tradicionalmente consumidos e estudados na Ásia e Europa (verde e preto, respectivamente) não é expressivo no Brasil. A posição destacada do chá mate é indiscutível, sendo outros tipos de chás, como de frutas e de ervas, merecedores de atenção. Para se conhecer a composição destes chás em termos de flavonóis, aplicou-se a mesma metodologia usada para chás verde e preto. Os resultados obtidos estão apresentados na Tabela 3, e a Figura 4 mostra os cromatogramas dos chás nos quais foram encontrados flavonóis.

Nas folhas de camomila analisadas foi encontrada quantidade razoável de quercetina, embora cerca de três vezes menor que os teores presentes em chás verde e preto. Em boldo, observou-se quantidade um pouco superior de quercetina, muito embora o que chama a atenção é o teor de kaempferol, que foi maior, dentre os chás analisados neste trabalho. Em morango desidratado para infusão, para o qual foi analisada apenas a única marca encontrada no mercado, a quercetina foi o único flavonol presente e em quantidade bem reduzida.

Por fim, na erva mate, a quercetina teve valor comparável ao dos chás verde e preto, embora o kaempferol esteja em baixos teores. Curiosamente, nenhum flavonol foi encontrado no chá mate, apesar deste ser proveniente de mesma fonte que a erva mate. Uma explicação possível seria o efeito do processamento sobre cada um dos produtos, atribuindo-lhes características distintas. A torragem das folhas para obtenção do chá mate poderia ter degradado os flavonóis. 


\section{4 - CONCLUSÕES}

Os teores de flavonóis miricetina, quercetina e kaempferol encontrados em chás verde e preto comercializados no Brasil são comparáveis aos resultados encontrados na literatura. Miricetina não foi encontrada nos chás de frutas, de flores e de ervas consumidos no Brasil, enquanto que a quercetina foi observada em quatro (camomila, boldo, morango e erva mate) em uma faixa menor que a de chás verde e preto, com exceção da erva mate, que estava com valores semelhantes. Duas amostras (boldo e erva mate) apresentaram kaempferol, no boldo em concentração igual ou maior que as de chás verde e preto. Desta constatação, conclui-se que estes chás são fontes de flavonóis na dieta brasileira, embora com teores menos significativos que em chás verde e preto.

\section{5 - REFERÊNCIAS BIBLIOGRÁFICAS}

[1] AHERNE, S.A.; O'BRIEN, N.M. Dietary flavonols: chemistry, food content and metabolism. Nutr., v. 18, n. 1, p. 75-81, 2002.

[2] COOK, N.C.; SAMMAN, S. Flavonoids - Chemistry, metabolism, cardioprotective effects, and dietary sources. Nutr. Biochem., v. 7, p. 66-76, 1996.

[3] DUFRESNE, C.; FARNWORTH, E. Tea, kombucha, and health: a review. Food Res. Int., v. 33, n. 6, p. 409-421, 2000.

[4] GELEIJSE, J.M.; LAUNER, L.J.; HOFMAN, A.; POLS, H.A.P.; WITTEMAN, J.C.M. The flavonoids may protect against atherosclerosis. Arch. Inter. Med., v. 159, p. 2.170-2.174, 1999.

[5] HERTOG, M.G.L. Epidemiological evidence on potential health properties of flavonoids. Proc. Nutr. Soc., v. 55, p. 385-397, 1996.

[6] HERTOG, M.G.L.; HOLLMAN, P.C.H.; van de PUTTE, B. Content of potentially anticarcinogenic flavonoids of tea infusions, wines and fruit juices. J. Agric. Food Chem., v. 41, n. 8, p. 1.242-1.246, 1993.

[7] HOLLMAN, P.C.H. Evidence for health benefits of plant phenols: local or systemic effects? J. Sci. Food Agric., v. 81, n. 9 , p. $842-852,2001$.

[8] HOLLMAN, P.C.H.; ARTS, I.C.W. Flavonols, flavones and flavanols - nature, occurrence and dietary burden. $\mathbf{J}$. Sci. Food Agric., v. 80, n. 7, p. 1.081-1.093, 2000.

[9] HOLLMAN, P.C.H.; KATAN, M.B. Absorption, metabolism and health effects of dietary flavonoids in man. Biomed. Pharmacother., v. 51, n. 8, p. 305-310, 1997.
[10] HOLLMAN, P.C.H.; KATAN, M.B. Dietary flavonoids: intake, health effects and bioavailability. Food Chem. Toxicol., v. 37, n. 9-10, p. 937-942, 1999.

[11] INSTITUTO BRASILEIRO DE GEOGRAFIA E ESTATÍSTICA (IBGE). Pesquisa de orçamentos familiares - POF 2003-2003 - análise da disponibilidade domiciliar de alimentos e do estado nutricional no Brasil. Disponível em http://www.ibge.gov.br. Acesso em: 22 dez. 2005.

[12] KARAKAYA, S.; EL, S.N. Quercetin, luteolin, apigenin and kaempferol contents of some foods. Food Chem., v. 66, n. 3, p. 289-292, 1999.

[13] KURODA, Y.; HARA, Y. Antimutagenic and anticarcinogenic activity of tea polyphenols. Mutation Res., v. 436, p. 69-97, 1999.

[14] MATTILA, P.; ASTOLA, J.; KUMPULAINEN, J. Determination of flavonoids in plant material by HPLC with diode-array and electro-array detections. J. Agric. Food Chem., v. 48, n. 11, p. 5.634-5.841, 2000.

[15] SCHRAMM, D.D.; GERMAN, J.B. Potential effects of flavonoids on the etiology of vascular disease. J. Nutr. Biochem., v. 9, n. 10, p. 560-566, 1998.

[16] TIJBURG, L.B.M.; MATTERN, T.; FOLTS, J.D.; WEISGERBER, U.M.; KATAN, M.B. Tea flavonoids and cardiovascular diseases: a review. Crit. Rev. Food Sci. Nutr., v. 37, n. 8, p. 771-785, 1997.

[17] TOYODA, M.; TANAKA, K.; HOSHINO, K.; AKIYAMA, H.; TANIMURA, A.; SAITO, Y. Profiles of potencially antiallergic flavonoids in 27 kinds of health tea and green tea infusions. J. Agric. Food Chem., v. 45, n. 7, p. 2.561-2.564, 1997.

[18] VISIOLI, F.; BORSANI, L.; GALLI, C. Diet and prevention of coronary heart disease: the potential role of phytochemicals. Cardiovas. Res., v. 47, n. 3, p. 419-425, 2000.

[19] WANG, H.; HELLIWELL, K. Determination of flavonols in green and black tea leaves and green tea infusions by high-performance liquid chromatography. Food Res. Int., v. 34, n. 2-3, p. 223-227, 2001.

[20] WANG, H.; PROVAN, G.J.; HELLIWELL, K. Tea flavonoids: their functions, utilization and analysis. Trends Food Sci Technol., v. 11, n. 4-5, p. 152-160, 2000.

[21] YANG, C.S.; LANDAU, J.M.; HUANG, M.-T.; NEWMARK, H.L. Inhibition of carcinogenesis by dietary polyphenolic compounds. Annu. Rev. Nutr., v. 21, p. 381-406, 2001.

\section{6 - AGRADECIMENTOS}

À Capes pela concessão de bolsa à primeira autora e à Fapesp pelo financiamento do projeto Pronex Processo $n^{\circ} 2003 / 10151-4$. 